\title{
A thematic analysis of therapists' perspectives on therapeutic alliance rupture moments
}

\author{
Gonca Soygüt, ${ }^{1}$ İsmail Volkan Gülüm² \\ ${ }^{1}$ Department of Psychology, İstanbul Şehir University, Istanbul; ${ }^{2}$ Department of Psychological Counselling and Guidance, Dumlupınar \\ University, Kütahya, Turkey
}

\begin{abstract}
This study aimed to qualitatively examine the perspectives of therapists using different theoretical orientations on rupture moments. The study features a qualitative research design. Six different therapy session segments were presented to the participants and questions were asked to gather their perspectives on the segments. The thematic analyses conducted on 20 therapists' evaluations on the 6 rupture segments of 5 patients were based on two categories: i) the causes of the rupture moments, ii) the recommendations for resolution. Findings revealed that therapists are more likely to report patients' negative contribution as the main cause of rupture moments. Participants attributed less importance to the negative contribution of the therapist or to the therapist-patient relationship in rupture moments, and therapists tended to suggest mostly technical resolutions to ruptures. This second-generation alliance research draws attention to relational aspects of the rupture resolution processes for a positive outcome. However, our findings yielded that there was a lack in therapists' evaluations in addressing the contribution of the therapists and/or therapist-patient relationship to rupture moments. This highlights the importance of supervision training to foster therapists' awareness of rupture moments and develop their skills for resolution in the context of the therapist-patient relationship.
\end{abstract}

Key words: Therapeutic alliance rupture; Therapists' perspectives; Thematic analysis.

\section{Introduction}

A body of psychotherapy research over several decades has consistently demonstrated that the quality of the therapeutic alliance is the best predictor of therapy

Correspondence: Gonca Soygüt, Department of Psychology, İstanbul Şehir University, Istanbul, Turkey.

Tel./Fax: +90.216 .4745353 .

E-mail: goncasoygutpekak@sehir.edu.tr

Contributions: all authors have met all of the authorship criteria of ICMJE.

Funding: this study was supported by the Scientific and Technological Research Council of Turkey (TÜBİTAK-SOBAG104 K082).

Citation: Soygüt, G., \& Gülüm, İ.V. (2016). A thematic analysis of therapists' perspectives on therapeutic alliance rupture moments. Research in Psychotherapy: Psychopathology, Process and Outcome, 19(2), 113-123. doi: 10.4081/ripppo.2016.235

Received for publication: 11 July 2016.

Revision received: 29 September 2016.

Accepted for publication: 30 September 2016.

This work is licensed under a Creative Commons Attribution NonCommercial 4.0 License (CC BY-NC 4.0).

(C) Copyright G. Soygüt and I. Volkan Gülüm, 2016

Licensee PAGEPress, Italy

Research in Psychotherapy:

Psychopathology, Process and Outcome 2016; 19:113-123

doi:10.4081/ripppo.2016.235 outcome (Bickman, Andrade, Athay, Chen, Nadai, Jordan-Arthur, Karver, 2012; Horvath, Del Re, Fluckiger \& Symonds, 2011; Martin, Garske \& Davis, 2000). Thus, psychotherapy researchers have focused on the exploration of those factors that lead to a good therapeutic alliance. Different lines of research have highlighted the importance of various factors on the formation and maintenance of a good alliance as follows: attachment styles (e.g. Kivlighan, Patton \& Foote, 1998; Mallinckrodt, 1991; Mallinckrodt, Coble \& Gantt, 1995), patients' expectations (e.g. Joyce \& Piper, 1998; Joyce, Ogrodniczu, Piper \& McCallum, 2003), interpersonal problems (e.g. Connolly Gibbons, Crits-Christoph, de la Cruz, Barber, Siqueland, Gladis, 2003; Muran, Segal, Samstag \& Crawford, 1994), and therapists' characteristics (e.g. Lutz, Leon, Martinovich, Lyons \& Stiles, 2007; Najatavis \& Strupp, 1994). In contrast to earlier findings, recent studies have drawn attention to the evidence that therapists are more likely to negatively contribute to the therapeutic alliance than patients (Baldwin, Wampold \& Imel, 2007; Del re, Flückiger, Horvath, Symonds \& Wampold, 2012). Some therapists have been found to be more effective and better in alliance development than others (Lutz et al., 2007). Findings have pointed out that therapist experience alone is not significantly associated with the alliance (Dunkle \& Friedlander, 1996; Kivlighan et al., 1998).

In terms of conceptualization, following Bordin's trans-theoretical definition $(1979,1994)$, the alliance became an investigative tool for all psychotherapy approaches. According to Bordin, the therapeutic alliance is 
comprised of three intercorrelated components: agreement in tasks, goals and affective bond. In line with this, Safran and Muran (2000) pioneered a trend that they called second generation alliance research. These studies focused on rupture resolution in the therapeutic alliance in addition to studying the factors that contributed to the development of a good alliance (Safran, Muran, Samstag \& Stevens, 2002). Safran and Muran (2000) conceptualized alliance rupture moments as those when the relationship between the therapist and patient becomes strained, and consequently, the alliance is degraded. As in Bordin's conceptualization, ruptures can be observed as disagreements concerning the therapy tasks and goals, or as strains in the therapist-patient relationship (Safran et al., 2002). A rupture can be revealed in different phases of the psychotherapy process and in various ways. Ruptures may occur dramatically or may show themselves as very minor fluctuations, making them difficult for either the therapist or the patient to identify. More strikingly, Safran and Muran (2000) emphasised that these rupture resolution moments play a central role in the change process in psychotherapy. Specifically, Safran (1993) framed that i) a negative patient-therapist relationship is a risk of poor outcome or treatment failure; ii) ruptures play a role in exploring core dysfunctional interpersonal schemas; iii) rupture resolution moments might be an opportunity for the therapist to provide the patient a corrective emotional experience and change in dysfunctional interpersonal schemas. In their recent meta-analysis study, Safran, Muran and EubanksCarter (2011) demonstrated that the relationship between rupture resolution moments and outcome was .24 $(\mathrm{P}=.002)$ and the relationship between therapist intervention in therapeutic alliance ruptures and positive therapy outcome was $.65(\mathrm{P}<.001)$. These findings affirm that rupture and resolution are significant processes influencing outcome.

The aforementioned literature has pointed out that various factors were related to the development of a good alliance and that there is growing evidence on the key role of therapists' contributions. The second generation of alliance research has emphasised that the therapist's awareness of the exploration of rupture markers and development of resolution skills seems to be important for good outcome. These studies have also highlighted potentially negative consequences of not focusing on ruptures in a change process. Thus, we considered that examining therapists' perspectives on rupture moments would be a worthwhile endeavour, especially in the context of clinical implications. More specifically, we aimed to focus on the perspectives of therapists, from various psychotherapy traditions, in terms of the following questions in a qualitative research design: i) What are the therapists' perspectives on the causes of rupture moments?; ii) What are the recommendations of therapists to resolve these rupture moments?; iii) Are therapists' perspectives on the rupture resolution moments congruent with theoretical frameworks and the relevant literature?

\section{Materials and Methods}

\section{Design}

The dataset consisted of 48 cases and 742 sessions from two psychotherapy approaches [cognitive behavioural therapy (CBT) and schema therapy (ST)] between 2005 and 2014 in the Hacettepe University Psychotherapy Research Laboratory, Ankara, Turkey. Ethical approval was granted by the University Ethical Committee. After obtaining informed consent of therapists and patients, all sessions were video recorded and then transcribed.

In the scope of this study, therapeutic alliance rupture segments were determined based on the method described below in detail. These segments were then presented to the psychotherapy experts who were asked about their assessments on the cause of the ruptures and what could have been done to resolve these ruptures. The responses were qualitatively analysed.

\section{Identification of the rupture segments}

Therapeutic alliance rupture sessions were identified using the method of Strauss et al. (2006), which is based on Stiles et al.'s (2004) regression analysis. This method has the advantage of quantitative approach that can be easily and practically implemented. To identify rupture sessions in a dataset, all the patients completed the Working Alliance Inventory-Client form (WAI-C) during their therapy courses for each session. The WAI-C's mean (M) scores and standard deviations (SD) were calculated for each patient separately and following that, after excluding dropout and researcher cases, the mean standard deviation was calculated for the whole dataset $(\mathrm{M}=.32, \mathrm{SD}=.20)$. The mean standard deviation value acquired from the whole dataset indicated a significant change in the alliance. According to this, there are several necessities required to identify a rupture session: there must be i) at least three alliance scores belonging to each psychotherapy process to observe shifts; ii) a decrease in alliance scores of an amount at least the same as the mean SD score; iii) an increase in the alliance scores of an amount at least the same as the mean SD score; and iv) no other fluctuation in the alliance scores within the same range (Strauss et al., 2006). Since this study did not focus on the repair process, criterion iv) was not applied.

After the sessions were identified, the second author inspected the sessions second by second and identified the rupture segments based on Eubanks, Safran and Muran's (2015) manual on therapeutic alliance ruptures and resolutions. The first author reviewed the segments and rupture markers and made quality check of the segments.

The sessions were then assigned to the participant therapists. The demographic information of the patients and descriptive characteristics of the assigned sessions are presented in Table 1. The rupture types according to Eu- 
banks, Muran and Safran (2015) are also specified in Table 1 for descriptive purposes.

\section{Participants}

All participants were recruited by the snowball sampling method. The inclusion criteria were being a psychotherapy practitioner and a clinical psychologist or a psychiatrist. Twenty participants were included and the segments were sent to them, encrypted by safe electronic link.

The following two questions were asked to the participants: i) What do you think about the causes of the struggle?; ii) How would you solve this struggle? Four of the participants were male (20\%), 16 female (80\%); 5 participants were psychiatrists (25\%), 15 were clinical psychologist (75\%); 8 were CBT experts $(40 \%), 8$ were psychoanalytic psychotherapists (40\%), 3 were schema therapists $(15 \%)$ and 1 was a positive psychotherapy expert (5\%). The age range of the participants was 25-55 $(\mathrm{M}=33.70, \mathrm{SD}=4.08)$ and the psychotherapy experience range was between 2 and 30 years $(\mathrm{M}=9, \mathrm{SD}=7.76)$.

\section{The researchers' role}

Since the researchers are a part of the data obtaining and knowledge generation process in qualitative studies, their possible biases could confound variables (Ambert, Adler, Adler \& Detzner, 1995). Reporting their potentially confounding characteristics is a way to prevent this: the authors were trained for both cognitive interpersonal therapy and ST, which are basically relational approaches. That is to say, they mainly focused on the rupture resolution process as a key for the therapeutic change in their practices and research area as well.

The first author carried out all the coding. Initially, the codes were based on the data using a trans-theoretical framework. The generated codes were regrouped according to the Bordin's $(1979,1994)$ categorization (bond, task and goal), and after generating the primary codes, themes and categories were generated during a meeting in which both the researchers participated.

To prevent possible artefacts, the following steps were taken: i) previous literature knowledge was used to determine the rupture sessions; ii) researchers' cases were excluded from the dataset; iii) MAXQDA 11 software (VERBI Software, 1998-2014) was used to handle human-based errors that may have occurred during coding.

\section{Data analysis}

Since it is important to focus on micro-processes in psychotherapy and bridge the gap between research and practice, qualitative research seems to be a great tool. We used the thematic analysis for this purpose because it is not dependent on a theory and has a potential

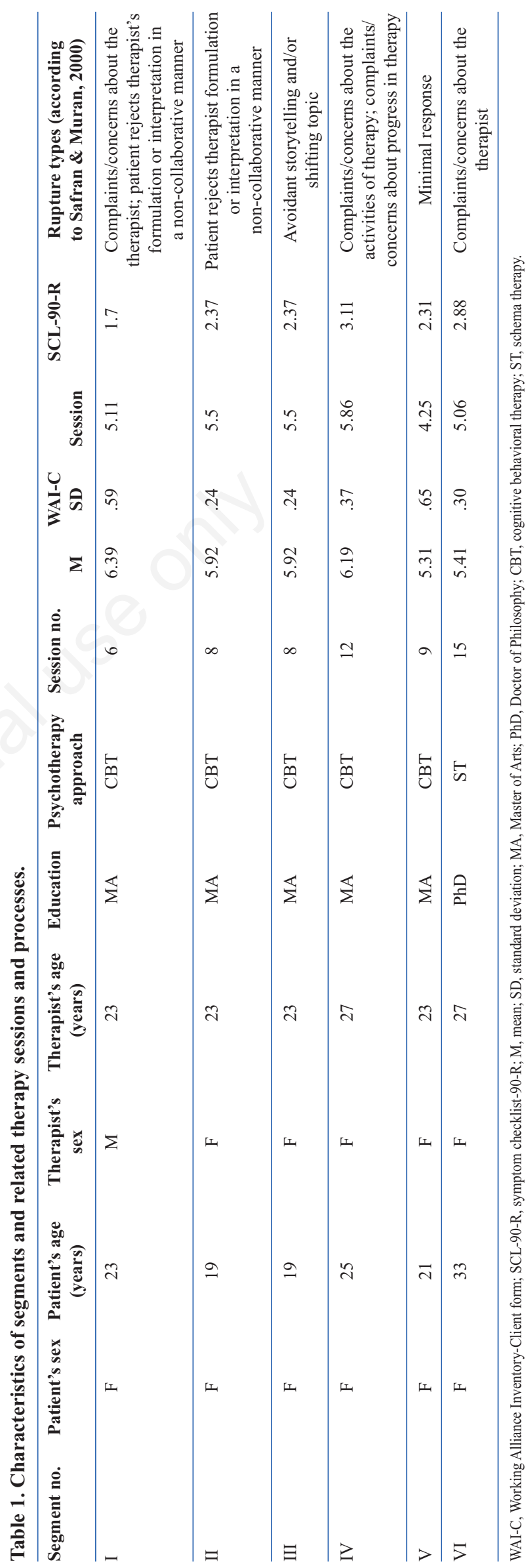


for rich and detailed result (Braun \& Clarke, 2006). As long as we did not use traditional data collection methods such as face-to-face interviews, we had research questions about participants' perspectives, and we preferred to compare responses in different ways, thematic analysis was the appropriate method to use.

The suggested steps by Braun and Clarke (2006) were adopted and applied in the thematic analysis; they emphasized that thematic analysis can be used for revealing, analyzing and reporting the patterns (themes) in data, enabling the dataset to be arranged, explained and interpreted. Accordingly, they suggested six phases for a thematic analysis: becoming familiar with the data; ii) generating initial codes; iii) searching for themes; iv) reviewing themes; v) defining and naming themes; vi) producing the report.

According to these steps, in the current study we: i) read all the data before starting the coding; ii) generated initial codes based on the first reading and coded all of the data in the second reading; iii) searched for potential themes and sub-themes across the codes based on the initial codes; iv) reviewed potential themes and organized a thematic map; v) defined themes and wrote descriptions to them; vi) wrote vivid examples, produced tables and figures to provide coherent and logical report.

The current study aimed to investigate the participants' views on therapeutic alliance ruptures by using thematic analysis. The coding was done by the first author; codes, themes and the patterns were audited and confirmed by the second author. All of the responses were coded individually. After the coding was completed, all the responses were reviewed. Thus, we endeavoured to establish intra- and interparticipant consistencies. In the current study, codes are gathered under two themes (here, causes and resolution recommendations). In the cause theme, there are 3 sub-themes and 11 codes; in the resolution recommendations theme, there are 2 sub-themes and 9 codes.

As noted earlier, we used Eubanks et al. (2015) manual to identify the segments. Initially, we planned to use this manual for coding the thematic analyses as well. However, since we had limited response from participants, we were unable to base on Eubanks et al.'s manual (2015) and had to prefer to use Bordin's framework (1994) as a more global categorization way of coding.

\section{Results}

\section{Main themes}

The produced themes were handled based on the two questions asked to the participants. According to this, the causes of the struggle were divided into three sub-themes: i) problems arising from the therapist-patient pair; ii) problems arising from the patient; iii) problems arising from the therapist. The resolution recommendations were divided into two sub-themes: i) technically oriented recommendations; and ii) relationship oriented recommen- dations. Observations of these themes and sub-themes are discussed below.

\section{Causes: problems arising from the therapist-patient pair}

Parallel to the theoretical background of the therapeutic alliance and alliance rupture (Bordin, 1979; Safran et al., 2002) this sub-theme is divided into four codes: i) rupture in goals [participant (P)20: This might be because of the thoughts/situations addressed by the therapist are secondary/peripheral for the patient.]; ii) rupture in tasks (P20: homework reprimand, confrontation does not work...); iii) rupture in bonds (P5: Patient does not feel the unconditional positive regard in the therapist-patient relationship.); and iv) unidentified rupture (P2: Actually, it is difficult to produce ideas about what is the cause of this struggle. But it's clear that there is a strain.).

\section{Causes: problems arising from the patient}

Similarly, this sub-theme also reflects the three components of the alliance. Additionally, there are five codes: i) rupture in goals (P10: The patient's expectations do not fit with the goals); ii) rupture in tasks (P16: The client might not exactly know about the tasks and method. Maybe does not understand the rationale or might think it's not appropriate/functional for his/her problem); iii) rupture in bonds (P9: I would think that the strain the patient experiences is caused by the expectations raised from the therapist-patient relationship, and this might be a reflection of a relationship with significant others in his/her life.); iv) problems concerning therapy readiness (P3: The patient's resistance might be due to not being ready to talk.); and v) life events (outside of therapy) (P13: The patient could have a life crisis during this process.).

\section{Causes: problems arising from the therapist}

This sub-theme is divided into three codes: i) rupture in goals (P16: They don't seem to have an agreement about the tasks. More importantly, the goals look different. The therapist seems to focus on the goals more and missed the patient's needs); ii) rupture in tasks (P12: The therapist did not give enough behavioural or verbal feedback to the patient in the session. Instead of contributing to the patient's own solution-seeking process he/she directly seeks a suggestion or guidance); and iii) rupture in bonds (P12: Regardless of the fact that the patient wants to talk about his/her relationship with the therapist, the therapist avoids that).

\section{Resolution recommendations: technically oriented recommendations}

This sub-theme has six different codes: i) giving instructions about the treatment rationale and therapy course; ii) focusing on the patient's needs using techniques; iii) focusing on the patient's feelings using techniques; iv) referring to other therapists/therapy approaches or searching for guidance from a different ap- 
proach; v) reviewing previous session ruptures; vi) general (P10: Without changing the agenda, an emphasis could be made by telling how some thoughts might be harder to change). Most of the codes reflect their content, hence only an example for the last code is presented.

\section{Resolution recommendations: relationship oriented recommendations}

This sub-theme also includes three codes: i) focusing on the patient's relational needs (P9: Using my relationship with the patient, I would try to gain knowledge about where did he/she experience the same thing. What was the similarity in the strain, what was the pattern of the problem? I would try to understand this pattern and then take action to make changes in intellectual and behavioural aspects); ii) meta-communication (P11: Probably I would get angry, try to find the cause of this anger, share the feelings about his/her attitudes and try to learn his/her thoughts about my disclosure. Thereafter, I'd question his/her expectations from others in similar situations); and iii) general (P17: I would emphasise that this is understandable and reasonable questioning).

\section{Characteristics of rupture causes and resolution recommendations}

Responses of participants to the rupture causes are presented in Figure 1 based on Table 2. Frequencies were computed by summing the number of codes that were used during the analysis for each response.

These features arose when participants reflected their interpretations on the causes of ruptures. According to the participants' perspectives, the most prominent rupture causes were: patient/low bond alliance, therapist/low task alliance, patient/low task alliance, patient readiness and therapist-patient pair/low task alliance. Life events (outside of therapy) are only mentioned once.

With respect to the causes of rupture, participants first put emphasis on the patients, before considering the therapist and then the therapist-patient pair. While conducting the analyses, it became clear that some of the participants focused mostly on the therapists while some focused mostly on the patients. Most of the bond components of the therapeutic alliance focused on the patients' accounts.

Participants mostly emphasized the patients or therapists separately. This might itself cause stress on the rela-

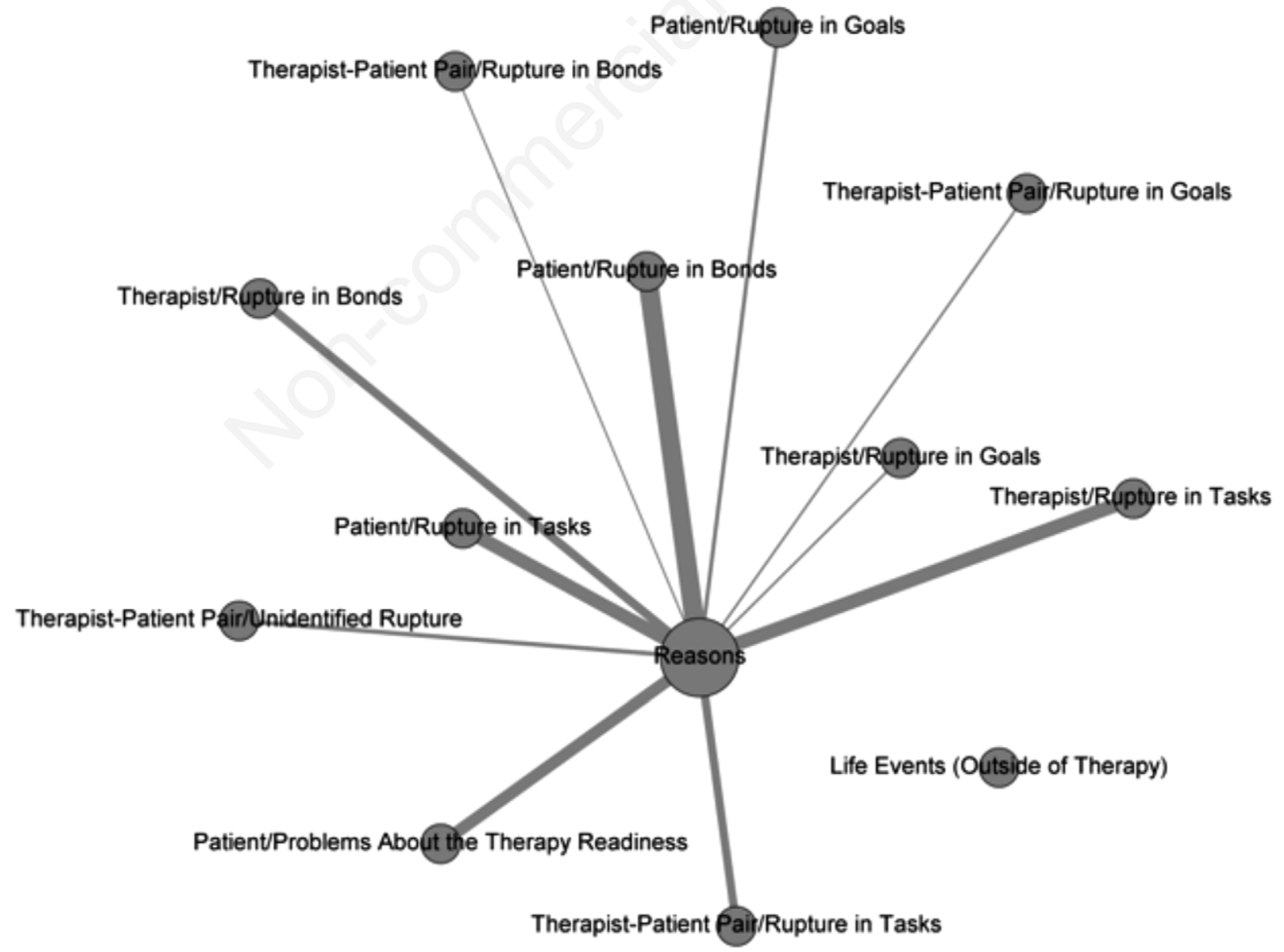

Figure 1. The web of rupture cause theme: thicker lines indicate stronger relationships. 
tional aspect of the ruptures. The responses of the participants to the resolution recommendations are presented in Figure 2 and Table 3.

These features arose during the resolution recommendations. Participants' most prominent recommendations were technically oriented recommendations.

In tandem with not focusing on the therapist-patient relationship in respect of the causes of rupture, the frequency of relationship oriented recommendations was also relatively low. The technically oriented recommendations were not elaborated on by the participants (P15: Rather than using yes or no (closed) questions, it would be helpful to use open-ended questions). They were ob- served mostly specific to the instructions about the treatment rationale and therapy course, such as focusing on the patient's feelings using techniques and focusing on the patient's needs using techniques.

The relationship oriented recommendations were also generally not elaborated (P13: Stop talking about the homework and start talking about this situation of the patient. The causes of the issue and what can be done about this could be discussed). The specific relationship oriented recommendations were the most common themes noted, followed by focusing on the patient's relational needs and meta-communication. While the participants focused on the patient's relational needs as a part of the relationship

Table 2. The frequency of themes, sub-themes, and codes in rupture causes.

\begin{tabular}{llc}
\hline Causes (themes, sub-themes, and codes) & & Frequency (n) \\
\hline Therapist-patient pair & Therapist-patient pair/rupture in goals & 6 \\
& Therapist-patient pair/rupture in tasks & 18 \\
& Therapist-patient pair/rupture in bonds & 5 \\
& Therapist-patient pair/unidentified rupture & 10 \\
& Total & 39 \\
\hline Patient & Patient/rupture in goals & 11 \\
& Patient/rupture in tasks & 30 \\
& Patient/rupture in bonds & 41 \\
& Patient/problems about the therapy readiness & 26 \\
& Life events (outside of therapy) & 1 \\
& Total & 109 \\
\hline Therapist & Therapist/rupture in goals & 6 \\
& Therapist/rupture in tasks & 30 \\
& Therapist/rupture in bonds & 19 \\
& Total & 55 \\
\hline
\end{tabular}

Table 3. The frequency of themes, sub-themes, and codes in resolution recommendations.

\begin{tabular}{|c|c|c|}
\hline Recommendations (themes, sub-themes, and codes) & & Frequency (n) \\
\hline \multirow[t]{7}{*}{ Technically oriented recommendations } & $\begin{array}{l}\text { Technically oriented recommendations/giving instructions } \\
\text { about treatment rationale and therapy course }\end{array}$ & 19 \\
\hline & $\begin{array}{l}\text { Technically oriented recommendations/focusing on } \\
\text { patient's need by techniques }\end{array}$ & 15 \\
\hline & $\begin{array}{l}\text { Technically oriented recommendations/focusing on patient's } \\
\text { feelings by techniques }\end{array}$ & 17 \\
\hline & $\begin{array}{l}\text { Technically oriented recommendations/referring to other therapists } \\
\text { therapy approach or searching for guidance from a different } \\
\text { psychotherapy approach }\end{array}$ & 2 \\
\hline & $\begin{array}{l}\text { Technically oriented recommendations/reviewing the previous } \\
\text { sessions' ruptures }\end{array}$ & 2 \\
\hline & Technically oriented recommendations/general & 53 \\
\hline & Total & 108 \\
\hline \multirow[t]{4}{*}{ Relationship oriented recommendations } & $\begin{array}{l}\text { Relationship oriented recommendations/focusing on patient's } \\
\text { relational needs }\end{array}$ & 19 \\
\hline & Relationship oriented recommendations/meta-communication & 16 \\
\hline & Relationship oriented recommendations/general & 25 \\
\hline & Total & 60 \\
\hline
\end{tabular}


oriented recommendations, the focus was mostly on the patients, and the participants missed recommendations regarding the therapist-patient pair.

\section{Differentiation among session segments}

The distributions of rupture causes and resolution recommendations for all segments are presented in Table 4. As shown in Table 4, segment IV was the most difficult for the participants. The variety of ideas produced about the rupture causes was relatively low. Although the participants were able to produce one or more ideas in the other segments, some of the participants said there was no rupture for this segment. However, even though there was a struggle to produce ideas on possible rupture causes, the highest number of relationship oriented recommendations was produced for this segment (Table 4). The highest number of rupture causes occurred in segment I, in which the technical and relationship oriented recommendations were balanced.

The lowest number of relationship oriented, yet the highest number of technical recommendations, was seen in segment VI, where the frequency of identifying rupture

Table 4. The frequency of rupture cause and resolution recommendation for each segment.

\begin{tabular}{lcccccc}
\hline Segment no. & & \multicolumn{2}{c}{ Rupture cause } & & \multicolumn{2}{c}{ Resolutions recommendations } \\
Patient & Therapist & Therapist-patient pair & Total & Relationship oriented & $\begin{array}{c}\text { Technically oriented } \\
\text { Total }\end{array}$ \\
\hline I & 24 & 14 & 12 & 50 & 13 & 18 \\
\hline II & 15 & 7 & 9 & 31 & 12 & 17 \\
\hline III & 17 & 10 & 3 & 30 & 10 & 18 \\
\hline IV & 10 & 8 & 2 & 20 & 16 & 28 \\
\hline V & 26 & 12 & 6 & 44 & 8 & 26 \\
\hline VI & 17 & 4 & 7 & 28 & 1 & 26 \\
\hline
\end{tabular}

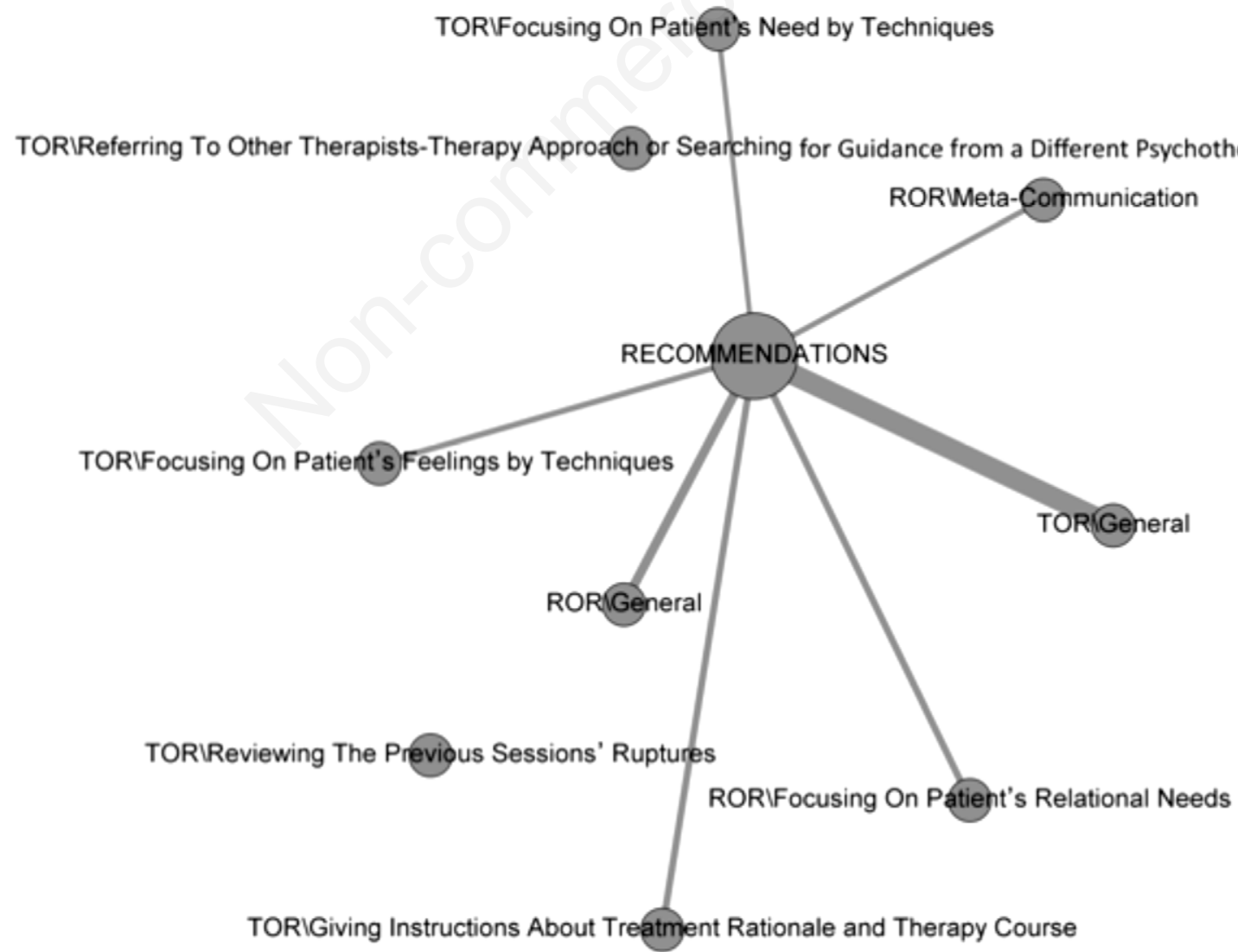

Figure 2. The web of resolution recommendations' theme. TOR, technically oriented recommendations; ROR, relationship oriented recommendations. 
causes was the second lowest among all segments. However, different from segment IV, this segment had the lowest number of relationship oriented, yet the highest number of technical recommendations.

\section{Discussion}

This study aimed to examine the perspectives of therapists from different theoretical orientations on rupture moments. The thematic analyses conducted were based on two general categories: i) the causes of the rupture moments; ii) the recommendations for resolution.

In the first category, findings regarding causes of the rupture moments reveal that therapists are more likely to report the patients' contribution as the main causes of the rupture moments than the therapist's or the therapist-patient relationship's contribution. In other words, they attributed less importance to the contribution of therapists or the therapist-patient relationship in rupture moments. Furthermore, even if some participants emphasized the therapists' contribution as the cause of the rupture, they overlooked the therapist-patient relationship. As a consequence, they overlooked the relational aspect of the rupture in the therapeutic alliance. Considering that the alliance or the rupture in the alliance are concepts referring to both the therapist's and the patient's mutual contributions, the resolution of the ruptures requires moment-by-moment awareness, attunement and monitoring of the process by therapists. The tendency observed in our participants might be a reflection of a lack of awareness of rupture moments, and this is a major obstacle in facilitating resolution of ruptures in the alliance. Accordingly, we can speculate that participants might tend to overlook their own role in the therapy process, particularly the key role of the therapeutic relationship itself, when considering rupture moments in their sessions.

The second category of the thematic analyses focused on was the recommendations for resolution. We observed that the technically oriented resolutions were more likely to be recommended than the relationally oriented ones. Although we did not analyze and differentiate the data by participants' specific psychotherapy orientations, our impression was that participants were more likely to recommend adherent resolutions from the framework of the psychotherapy approach they represented. Participants might have figured out that if there was a problem, then adherence to the technique might be low, so increasing the adherence could best facilitate resolution.

Along with the overall results of the causes of rupture moments, this was not a surprising finding. Considering that the general tendency of the participants was not associated with the relational perspective, they might have had a tendency to use/recommend other tools of their own psychotherapy approach. For instance, they tried to repair ruptures by focusing on specific techniques, such as using Socratic questioning. This can therefore be at- tributed as an adherence issue and be interpreted as participants producing technical recommendations based on their psychotherapy orientations when they face an impasse in a session. As a striking aspect, in line with this result, it can be thought that when there is a rupture, the therapist wants to increase the adherence to the therapy and use available resources. We can observe this tendency in the supervision processes, too. Nevertheless, the problem of whether we can repair ruptures by using a technically or relationally oriented approach is an important and challenging issue in the frame of psychotherapy research literature, considering the results of the negative relationship between a high level of adherence and the therapeutic alliance and therapy outcome (Castonguay, Goldfried, Wiser, Raue \& Hayes, 1996; Henry, Strupp, Butler, Schacht \& Binder, 1993; Soygüt, 2015). Given that the therapeutic alliance and the resolutions of rupture in the alliance are associated with therapy outcome (Bickman et al., 2012; Safran et al., 2011; Samstag, Batchelder, Muran, Safran \& Winston, 1998; Spinhoven, Giesen-Bloo, van Dyck, Kooiman, \& Arntz, 2007; Zuroff $\&$ Blatt, 2006), a poor alliance is identified as being related to dropout (Sharf, Primavera \& Diener, 2010). This tendency itself seems to be an inevitable difficulty in the change process.

As for the segment-based analyses, we attempted to analyze the general tendencies explained above at a microlevel and examine each segment separately, aiming to understand the differentiation between general tendencies and specific segments by particularly focusing on segments divergent from the general patterns. Accordingly, some of the segments differed slightly in terms of the overall patterns mentioned above. For instance, participants seemed relatively less clear about the cause of the rupture moments in segment IV and segment VI than other segments. They recommended mostly relationally oriented resolutions for segment IV, which included patient complaints about some of the therapy tasks. In segment VI, the second most challenging segment for the participants to find the cause of rupture moments, participants tended to recommend mostly technically oriented resolutions. This segment represents mainly the bond-related part of the alliance/alliance rupture. In terms of the content, patients were not confident about whether the therapists would be there for them. As an example: My friend said... 'You're not bonding with her, it's not love; you're telling something to her and she is obligated to listen...' Here you are doing your job; five seconds after the session, you won't be around. Overall, we speculate that the relationally oriented resolutions recommended by the participants in segment IV might be interpreted as reflections of technical aspects of certain psychotherapy approaches; similarly segment VI. Thus, initial observations and revealed results might suggest that if therapists know there is a rupture and are not sure about the rupture cause, they tend to prefer more technically oriented interventions. 
On the other hand, participants exhibited relatively more refined interpretations for segment I, which consisted of two different rupture markers. They also recommended both technically and relationally oriented resolutions in a balanced way. Perhaps it was easier and clearer in this segment for the participants to capture the cause of rupture moments and produce multiple and balanced technical and relational resolutions.

Overall, we consider that this study has some implications for the professional development of therapists. Because of the heterogeneity of the sample, although we did not examine therapeutic approaches, educational level, age and experience of the participants, our observation is that in the context of experience, the data shows that, although relatively more experienced therapists seem to be more confident with the technical part of the therapy process, they become more ignorant of the key role of the therapist in rupture moments. This finding can be discussed in the context of Bilican and Soygüt's (2015) study, which examined the professional development processes of therapists in Turkey. They found that experienced therapists are more likely to feel competent in their therapeutic work and interpersonal skills (i.e. being more natural in interacting with patients, exhibiting their understanding and concern to them, and attaining more precision, subtlety and finesse) than trainees. However, there was no difference between experienced therapists and trainees regarding their focus on what happened moment by moment during the sessions. We observed that there was a lack of process oriented perspective, even from the experienced therapists, which includes the mutual contribution of the therapist and the patient to the therapeutic process. Given that our sample has similarities with Bilican and Soygüt's (2015) study, we also concluded that our findings might be a reflection of the low levels of ongoing supervision programs and/or lack of focus on the process of and relational aspects in therapeutic work in the current training programs in Turkey.

\section{Methodological issues and study limitations}

Considering the methodological issues, the quantitative method of determining rupture moments used in this study seems to be an efficient way of capturing rupture moments, congruent with previous studies (Strauss et al., 2006). Furthermore, in the framework of qualitative studies, the number of the participants is at an acceptable level, and the heterogeneity of the psychotherapy approach represented in the study, regarding trans-theoretical perspectives, is also satisfactory.

Although there is a more refined sub-categorization of the rupture markers (Safran \& Muran, 2000), because of the limited responses from our participants, we had to use more general codes, namely, Bordin's trans-theoretical approach, in our thematic analyses. On the other hand, even if we considered forming a heterogeneous sample, another limitation might be related to the disadvantages of the snowball sampling methodology used in the study. This might lead to a bias as to the representation of the therapists having similar training, background or working at the same institution. Furthermore, even with both overt and covert characteristics, the chosen segments might not sufficiently reflect the rupture moments. Utilization of audio-visual materials could have provided some advantages; however, because of some ethical considerations and technical infeasibilities, we were not able to use videotaped versions of the segments. We attempted to overcome this disadvantage by focusing on segment by segment and taking into account differences and difficulties of each segment's possible characteristics.

\section{Conclusions}

In conclusion, this study provides a general understanding of the perspectives of therapists on rupture moments and their recommendations for the ways of dealing with them. Findings overall revealed that participants were more likely to report patients' contributions as the main causes of rupture moments, and they tended to recommend technically oriented resolutions. Therapists seemed to be neglectful of the relational nature of the therapeutic relationship. This might stem from the limited framework of supervision programs in Turkey. Considering that previous findings have highlighted that some therapists are more effective and successful in forming a therapeutic alliance (Lutz et al., 2007), rupture/alliance-focused training (Crits-Christoph, Crits-Christoph, \& Connolly Gibbons, 2010; Muran, Safran, \& Eubanks-Carter, 2010; Safran et al., 2014) might be an important contribution to both the professional development of therapists and might also provide benefit to patients (as well as mental health services). Thus, in terms of the implications for supervision training and clinical settings, it seems important to continue this line of research, especially in developing training guidelines (also covering visual materials), for the development of clinicians' awareness and resolution of rupture moments.

\section{References}

Ambert, A.-M., Adler, P.A., Adler, P., \& Detzner, D.F. (1995). Understanding and evaluating qualitative research. Journal of Marriage \& Family, 57(4), 879-908. doi:10.2307/353409

Baldwin, S.A., Wampold, B.E., \& Imel, Z.E. (2007). Untangling the alliance, outcome correlation: exploring the relative importance of therapist and patient variability in the alliance. Journal of Consulting \& Clinical Psychology, 75(6), 842852. doi:10.1037/0022-006X.75.6.842

Bickman, L., Andrade, A., Athay, M., Chen, J., Nadai, A., JordanArthur, B., Karver, M.S. (2012). The relationship between change in therapeutic alliance ratings and improvement in youth symptom severity: whose ratings matter the most? $A d$ ministration \& Policy in Mental Health \& Mental Health Services Research, 39(1/2), 78-89. doi: 10.1007/s10488-0110398-0 
Bilican, F.I., \& Soygüt, G. (2015). Türkiye'de Eğitim Sürecinde Olan ve Deneyimli Psikoterapistlerin Mesleki Gelişim Süreçleri [Professional development processes of trainee and experienced psychotherapists in Turkey]. Turkish Journal of Psychiatry, 26(4), 249-260. doi. 10.5080/u8024

Bordin, E.S. (1979). The generalizability of the psychoanalytic concept of the working alliance. Psychotherapy: Theory, Research \& Practice, 16(3), 252-260. doi: 10.1037/h0085885

Bordin, E.S. (1994). Theory and research on therapeutic working alliance: new directions. In: A.O. Horvath, \& L.S. Greenberg (Eds.) The working alliance: theory, research and practice içinde (pp. 13-37). New York: John Wiley \& Sons.

Braun, V., \& Clarke, V. (2006). Using thematic analysis in psychology. Qualitative Research in Psychology, 3(2), 77-101. doi: 10.1191/1478088706qp063oa

Castonguay, L.G., Goldfried, M.R., Wiser, S., Raue, P.J., \& Hayes, A.M. (1996). Predicting the effect of cognitive therapy for depression: a study of unique and common factors. Journal of Consulting and Clinical Psychology, 64(3), 497504. doi:10.1037/0022-006X.64.3.497

Crits-Christoph, P., Crits-Christoph, K., \& Connolly Gibbons M.B., (2010). Training in alliance-fostering techniques. In: J.C. Muran \& J.P. Barber (Eds.) The therapeutic alliance: an evidence-based guide to practice (pp. 304-319). New York, NY: Guilford Press.

Connolly Gibbons, M.B., Crits-Christoph, P., de la Cruz, C., Barber, J.P., Siqueland, L., \& Gladis, M. (2003). Pretreatment expectations, interpersonal functioning, and symptoms in the prediction of the therapeutic alliance across supportive-expressive psychotherapy and cognitive therapy. Psychotherapy Research, 13(1), 59-76. doi:10.1093/ $\mathrm{ptr} / \mathrm{kpg} 007$

Del Re, A.C., Flückiger, C., Horvath, A.O., Symonds, D., \& Wampold, B.E. (2012). Therapist effects in the therapeutic alliance-outcome relationship: a restricted-maximum likelihood meta-analysis. Clinical Psychology Review, 32(7), 642-649. doi: http://dx.doi.org/10.1016/j.cpr.2012.07.002

Dunkle, J.H. \& Friedlander, M.L. (1996). Contribution of therapist experience and personal characteristics to the working alliance. Journal of Counseling Psychology, 43(4), 456-460. doi: 10.1037/0022-0167.43.4.456

Eubanks, C.F., Muran, J.C., \& Safran, J.D. (2015). Rupture Resolution Rating System (3RS): manual. New York, NY: Mount Sinai-Beth Israel Medical Center.

Henry, W.P., Strupp, H.H., Butler, S.F., Schacht, T.E., \& Binder, J.L. (1993). Effects of training in time-limited dynamic psychotherapy: changes in therapist behavior. Journal of Consulting and Clinical Psychology, 61, 434-440. doi: 10.1037/0022-006X.61.3.434

Horvath, A.O., Del Re, A.C., Flückiger, C., \& Symonds, D. (2011). Alliance in individual psychotherapy. Psychotherapy, 48(1), 9-16. doi: 10.1037/a0022186

Joyce, A.S., Ogrodniczuk, J.S., Piper, W.E., \& McCallum, M. (2003). The alliance as mediator of expectancy effects in short-term individual therapy. Journal of Consulting and Clinical Psychology, 71(4), 672-679. doi: 10.1037/0022006X.71.4.672

Joyce, A.S., \& Piper, W.E. (1998). Expectancy, the therapeutic alliance, and treatment outcome in short-term individual psychotherapy. The Journal of Psychotherapy Practice and Research, 7(3), 236-248.

Kivlighan, D.M., Patton, M.J., \& Foote, D. (1998). Moderating effects of client attachment on the counselor experience- working alliance relationship. Journal of Counseling Psychology, 45(3), 274-278. doi: 10.1037/0022-0167.45.3.274

Lutz, W., Leon, S.C., Martinovich, Z., Lyons, J.S., \& Stiles, W.B. (2007). Therapist effects in outpatient psychotherapy: a three-level growth curve approach. Journal of Counseling Psychology, 54, 32-39. doi: 10.1037/0022-0167.54.1.32

Mallinckrodt, B. (1991). Clients' representations of childhood emotional bonds with parents, social support, and formation of the working alliance. Journal of Counseling Psychology, 38(4), 401-409. doi: http://dx.doi.org/10.1037/0022-0167. 38.4 .401

Mallinckrodt, B., Coble, H.M., \& Gantt, D.L. (1995). Working alliance, attachment memories, and social competencies of women in brief therapy. Journal of Counseling Psychology, 42(1), 79-84. doi:10.1037/0022-0167.42.1.79

Martin, D.J., Garske, J.P., \& Davis, M.K. (2000). Relation of the therapeutic alliance with outcome and other variables: a meta-analytic review. Journal of Consulting and Clinical Psychology, 68(3), 438-450. doi: 10.1037/0022-006X.68. 3.438

Muran, J.C., Safran, J.D., \& Eubanks-Carter, C. (2010). Developing therapist abilities to negotiate alliance ruptures. In: J.C. Muran \& J.P. Barber (Eds.) The therapeutic alliance: an evidence-based guide to practice (pp. 320-340). New York, NY: Guilford Press.

Muran, J.C., Segal, Z.V., Samstag, L.W., \& Crawford, C.E. (1994). Patient pretreatment interpersonal problems and therapeutic alliance in short-term cognitive therapy. Journal of Consulting and Clinical Psychology, 62(1), 185-190. doi:10.1037/0022-006X.62.1.185

Najavits, L.M., \& Strupp, H.H. (1994). Differences in the effectiveness of psychodynamic therapists: a process-outcome study. Psychotherapy: Theory, Research, Practice, Training, 31(1), 114-123. doi: 10.1037/0033-3204.31.1.114

Safran, J.D. (1993). Breaches in the therapeutic alliance: an arena for negotiating authentic relatedness. Psychotherapy, 30(1), 11-24. doi:10.1037/0033-3204.30.1.11

Safran, J.D. \& Muran, J.C. (2000). Negotiating the therapeutic alliance: a relational treatment guide. New York, NY: Guilford Press.

Safran, J., Muran, J.C., Demaria, A., Boutwell, C., EubanksCarter, C., \& Winston, A. (2014). Investigating the impact of alliance-focused training on interpersonal process and therapists' capacity for experiential reflection. Psychotherapy Research, 24(3), 269-285. doi:10.1080/10503307.2013. 874054

Safran, J.D., Muran, J.C., \& Eubanks-Carter, C. (2011). Repairing alliance ruptures. Psychotherapy, 48(1), 80-87. doi: $10.1037 / \mathrm{a} 0022140$

Safran, J.D., Muran, J.C., Samstag, L.W., \& Stevens, C. (2002). Repairing alliance ruptures. In: J.D. Norcross (Ed.), Psychotherapy relationships that work: therapist contributions and responsiveness to patients (pp. 235-254). New York, NY: Oxford University.

Samstag, L.W., Batchelder, S.T., Muran, J.C., Safran, J.D., Winston, A. (1998). Early identification of treatment failures in short-term psychotherapy: an assessment of therapeutic alliance and interpersonal behavior. Journal of Psychotherapy, Practice, \& Research, 7, 126-143.

Sharf, J., Primavera, L.H., \& Diener, M.J. (2010). Dropout and therapeutic alliance: a meta-analysis of adult individual psychotherapy. Psychotherapy, 47, 637-645. doi:10.1037/ a0021175 
Soygüt, G. (2015). An overview on the therapeutic alliance. Armenia: Regional Congress of Psychology.

Spinhoven, P., Giesen-Bloo, J., van Dyck, R., Kooiman, K., \& Arntz, A. (2007). The therapeutic alliance in schema-focused therapy and transference- focused psychotherapy for borderline personality disorder. Journal of Consulting \& Clinical Psychology, 75(1), 104-115. doi:10.1037/0022006X.75.1.104

Stiles, W.B., Glick, M.J., Osatuke, K., Hardy, G.B., Shapiro, D.A., Agnew-Davies, R., ..., Barkham, M. (2004). Patterns of alliance development and the rupture-repair hypothesis: are productive relationships u-shaped or v-shaped? Journal of Counseling Psychology, 51(1), 81-92. doi: 10.1037/00220167.51.1.81
Strauss, J.L., Hayes, A.M., Johnson, S.L., Newman, C.F., Brown, G.K., Barber, J.P., ..., Beck, A.T. (2006). Early alliance, alliance ruptures, and symptom change in a nonrandomized trial of cognitive therapy for avoidant and obsessive-compulsive personality disorders. Journal of Consulting \& Clinical Psychology, 74(2), 337-345. doi: 10.1037/ 0022-006x.74.2.337

VERBI Software (1998-2014). Maxqda 11 software for qualitative data analysis. Berlin: VERBI Software GmbH.

Zuroff, D.C., \& Blatt, S.J. (2006). The therapeutic relationship in the brief treatment of depression: contributions to clinical improvement and enhanced adaptive capacities. Journal of Consulting \& Clinical Psychology, 74(1), 130-140. doi:10.1037/0022-006X.74.1.130 